\title{
Integrated approaches to tackling health issues-related to agri-food systems
}

\author{
Hung Nguyen-Viet ${ }^{1,3}$ (D) $\cdot$ Delia Grace $^{2} \cdot$ John McDermott $^{4}$
}

Received: 8 August 2018 / Accepted: 9 August 2018/Published online: 10 August 2018

(C) Swiss School of Public Health (SSPH+) 2018

Hunger, malnutrition, and poor health are declining but stubborn development challenges, even in countries where other aspects of development are moving forward. The world population has reached 7.6 billion people in 2018 but 815 million people suffer from chronic undernourishment. While overall and long-term trends are positive, progress is vulnerable to short term and regional setbacks. Paradoxically, over nutrition is becoming a more important global issue, as the rates of obesity and overweight populations increase; as for hunger, this tends to be associated with poverty. Unbalanced diets and inadequate nutrition now underlie a triple burden of undernutrition, overweight and obesity, and micronutrient deficiency. The importance of these challenges is emphasized by their prominence of Sustainable Development Goals relating to food security, health, environment, and gender.

The implication is that food systems are failing to meet needs. The agri-food systems concept has been used to describe the full set of processes, activities, infrastructure, and environments that encompass the production, processing, distribution, waste disposal, and consumption of food. Food systems are multidimensional, with sociocultural, economic, environmental, and political aspects, and also complex, with multiple actors managing multiple

This editorial is part of the special issue "Environmental and health equity".

\footnotetext{
Hung Nguyen-Viet

h.nguyen@cgiar.org

John McDermott

j.mcdermott@cgiar.org

1 International Livestock Research Institute, Hanoi, Vietnam

2 International Livestock Research Institute, Nairobi, Kenya

3 Center for Public Health and Ecosystem Research (CENPHER), Hanoi University of Public Health, Hanoi, Vietnam

4 International Food Policy Research Institute, Washington, DC, USA
}

linked and nested agri-food value chains within dynamic and interactive food environments (A4NH 2018). This becomes a key concept to address nutrition, food security, and related health issues comprehensively.

As food security becomes better assured, and food supply more complex, the negative impacts of food production become more salient. Agri-food systems support life but can also contribute to poor health outcomes of both producers and consumers and have negative impacts on the environment. Environmental issues include pollution due to intensive farming systems (water pollution with excess use of pesticide and chemical fertilizers), climate change (GHG emission), and land degradation and erosion (Perry et al. 2013; Herrero and Thornton 2013).

Adverse human health issues include zoonotic diseases, antimicrobial resistance (AMR), occupational disease, unsafe food, and unbalanced diets causing malnutrition. Millions of people die from diseases that emerge from, or persist in, agricultural ecosystems: zoonoses (diseases transmissible between wildlife and domestic animals and human) and diseases recently emerged from animals make up $25 \%$ of the infectious disease burden in least developed countries and kill one in ten people who live there (Grace et al. 2012). Other urgent health problems related to agriculture include fungal toxins (mycotoxins) in crops and animal source foods, plant toxins, use of wastewater for agriculture, misuse of agricultural chemicals, and antibiotics, food adulteration, occupational hazards of food value chains; contribution of agriculture to climate change and impacts of this on disease; and health impacts of agricultural alteration of ecosystems (such as irrigation practices that promote malaria).

Agricultural systems are exacting a heavy biological cost, but health policy and programs often stop at the clinic door while agriculture initiatives rarely have 'enhancing health' as an articulated objective. A consensus is growing that the disconnect between agriculture, health, and nutrition is at least partly responsible for the disease burden associated with food and farming. The new CGIAR 
Research Program on Agriculture for Nutrition and Health is attempting to bridge this disconnect (A4NH 2018). $\mathrm{A} 4 \mathrm{NH}$, an Integrative Research Program, responds to the global challenge of improving food security, nutrition, and health, by taking a perspective that begins with consumption, rather than supply, of healthy, affordable, and safe foods. One component of this global program entitled 'Improving Human Health' has ambitious aims, including: (1) Agricultural research initiatives, including those in farming communities, measure health risks and benefits; (2) agricultural and public health policymakers and implementers deliver coordinated and effective solutions to cysticercosis and other zoonotic threats; and (3) public and private sector policymakers implement measures to reduce health risks from AMR in hot spot livestock systems. This calls for an integrated approach to control health related to agriculture and requires cross-sector collaboration. For example, to deal with the growing AMR issue, it is important to have an integrated surveillance system with a One Health approach (Nguyen-Viet et al. 2016).

Traditionally, public health experts have not been very engaged in health issues related to agriculture, while agriculture experts concentrated more on production and productivity and less on externalities. As we move toward a post-scarcity Anthropocene, it is time now for agricultural sector to engage public health people and also other stakeholders to address the agri-food system and health. Integrated approaches such as One Health and Ecohealth will be key to promote the health of human, animal, and environments in the future (Zinsstag et al. 2015). On the nutrition side, agriculture research needs to be fundamentally changed, from the current emphasis on commodities and supply-side goals to consumption and diets (McDermott et al. 2015).

Acknowledgements We thank the CGIAR Research Program on Agriculture for Nutrition and Health led by IFPRI for financial support. We gratefully acknowledge Marisa Mitchell for an English language review.

\section{References}

A4NH (2018) Agriculture for Nutrition and Health program. Institute Food Policy Research Institute. www.a4nh.cgiar.org. Accessed 7 Aug 2018

Grace D, Mutua F, Ochungo P, Kruska R, Jones K, Brierley L, Lapar L, Said M, Herrero M, Phuc PM, Thao NB, Akuku I, Ogutu F (2012) Mapping of poverty and likely zoonoses hotspots. Zoonoses Project 4. Report to the UK Department for International Development. ILRI, Nairobi

Herrero M, Thornton PK (2013) Livestock and global change: emerging issues for sustainable food systems. Proc Natl Acad Sci USA 110(52):20878-20881. https://doi.org/10.1073/pnas. 1321844111

McDermott J, Johnson N, Kadiyala S, Kennedy G, Wyatt AJ (2015) Agricultural research for nutrition outcomes-rethinking the agenda. Food Secur 7:593-607

Nguyen-Viet H, Chotinun S, Schelling E, Widyastuti W, Khong NV, Kakkar M, Beeche A, Jing F, Khamlome B, Tum S, Adisasmito W (2016) Reduction of antimicrobial use and resistance needs sectoral-collaborations with a One Health approach: perspectives from Asia. Int J Public Health. https://doi.org/10.1007/s00038016-0933-6

Perry BD, Grace D, Sones K (2013) Current drivers and future directions of global livestock disease dynamics. Proc Natl Acad Sci USA 110(52):20871-20877. https://doi.org/10.1073/pnas. 1012953108

Zinsstag J, Schelling E, Waltner-Toews D, Whittaker M, Tanner M (2015) One health: the theory and practice of integrated health approaches. CABI, Wallingford 